\title{
Afromontane Coelocorynus (Coleoptera: Scarabaeidae: Cetoniinae): Larval descriptions, biological notes and phylogenetic placement
}

\author{
Petr ŠÍPEK ${ }^{1}$, Bruce D. GILL ${ }^{2}$ and VAsily V. GREBENNIKOV ${ }^{2}$ \\ ${ }^{1}$ Department of Zoology, Faculty of Science, Charles University in Prague, Viničná 7, CZ-128 44 Praha 2, Czech Republic; \\ e-mail: sipekpetr@yahoo.com \\ ${ }^{2}$ Entomology Research Laboratory, Ottawa Plant and Seed Laboratories, Canadian Food Inspection Agency, K.W. Neatby Bldg., \\ 960 Carling Avenue, Ottawa, Ontario K1A 0C6, Canada; e-mails: bruce.gill@inspection.gc.ca; vasily.grebennikov@inspection.gc.ca
}

Key words. Coleoptera, Scarabaeoidea, Cetoniinae, Valgini, Trichiini, Cryptodontina, Coelocorynus, larvae, morphology, phylogeny, Africa, Cameroon, Mt. Oku

\begin{abstract}
This paper reports the collecting of adult beetles and third-instar larvae of Coelocorynus desfontainei Antoine, 1999 in Cameroon and provides new data on the biology of this high-altitude Afromontane genus. It also presents the first diagnosis of this genus based on larval characters and examination of its systematic position in a phylogenetic context using 78 parsimony informative larval and adult characters. Based on the results of our analysis we (1) support the hypothesis that the tribe Trichiini is paraphyletic with respect to both Valgini and the rest of the Cetoniinae, and (2) propose that the Trichiini subtribe Cryptodontina, represented by Coelocorynus, is a sister group of the Valgini: Valgina, represented by Valgus. The larvae-only analyses were about twofold better than the adults-only analyses in providing a phylogenetic resolution consistent with the larvae + adults analyses. Only one of the ten clades was consistently supported by the analyses of both the larval and adult datasets, while the remaining nine were invariably strongly supported by one but not the other analysis, thus highlighting the importance of employing different data so urces.
\end{abstract}

\section{INTRODUCTION}

The Afromontane beetle genus Coelocorynus (Figs 1-4) includes 18 named species, 15 of which were described in the last 10 years (Antoine 1999, 2003). The few known Coelocorynus specimens were predominantly recorded from altitudes between $2000 \mathrm{~m}$ and $3000 \mathrm{~m}$, with the lowest being $950 \mathrm{~m}$ and the highest $3900 \mathrm{~m}$. All but one Coelocorynus species are known from the EastAfrican highlands located within the triangle formed by southeast Ethiopia, central Tanzania and the easternmost part of the Democratic Republic of Congo (DRC). This genus is reported from the Bale Mountains (Ethiopia), Mt. Kenya and the Aberdare Mountains (Kenya), Mt. Elgon (Kenya/Uganda), the Usambara and Uluguru Mountains (Tanzania), and the Ruwenzori Mountains (along with some other closely adjacent ranges in the west) in Uganda/DRC. This predominantly East-African distributional pattern is disrupted by the Cameroonian species C. desfontainei Antoine, 1999, previously known from two males and two females from the Northwest province, including Bafut and Mt. Oku.

Phylogenetic affinities of Coelocorynus were uncertain. When proposed, the genus was grouped with the monotypic Cryptodontes Burmeister, 1847 and Pantodinus Burmeister, 1847 as sub-groups of Dynastinae (cited after Krikken, 1984: 39; the status of Scarabaeoidea familygroup names conventionally used throughout this paper are those of Smith, 2006) to form the subtribe Cryptodontina. Kolbe (1909) associated it with Platygenia Macleay, 1819 and Osmoderma Lepeletier \& Serville, 1825, thus transferring it into the poorly defined Trichiini. Krikken
(1984) revised the whole of the Cetoniinae ("Cetoniidae" in his sense) and transferred the genus Pantodinus into Incaina, another Trichiini subtribe. Recently, Micó et al. (2008) made the most comprehensive phylogenetic treatment of Cetoniinae so far, employing both larval and adult characters, and concluded that the tribe Trichiini (sensu Smith, 2006) consists of at least three separate lineages: (A) subtribe Trichiina, a sister group to the Valgini; (B) subtribe Osmodermatina, and (C) subtribe Incaina branching off subsequently from Cetoniinae s. str. (Cetoniinae without Trichiini and Valgini). Their analyses, however, did not include representatives of three subtribes critical for testing the basal branching events within the Cetoniinae, namely Microvalgina (Valgini), Platygeniina and Cryptodontina (both Trichiini).

This paper reports the discovery of a Coelocorynus breeding site in Cameroon and has six objectives: (1) provide a detailed description and illustrations of Coelocorynus larvae; (2) report observations on the biology of this poorly known genus; (3) hypothesise about the phylogenetic position of Coelocorynus; (4) test more rigorously the overall monophyly of Cetoniinae hypothesized by Micó et al. (2008); (5) evaluate the relative contribution of larval versus adult characters in resolving the phylogeny of our ingroup, and (6) indicate the most promising directions for future phylogenetic research on the Cetoniinae. Overall, we hope to add to our knowledge of pleurostict Scarabaeidae, a mega-diverse radiation of plant-eating beetles, which includes many agriculture and forestry pests such as "chafers" and "June beetles", and 
TABLE 1. Results of the 12 phylogenetic analyses (columns 1-12). "Dataset" row indicates the three datasets used in the analyses (larvae, adults and combined; characters 1-43, 44-81 and 1-81, respectively). "Ordered/unordered" row indicates whether some multistate characters $(7,11,13,16,25,30,37,52,54,67,77)$ were ordered. "Successive weighting" row indicates whether successive approximations were used for character weighting. Next three rows indicate tree length, consistency (CI) and retention (RI) indices, and the number of the shortest (= most parsimonious) trees obtained. Taxonomic abbreviations used in the left column are: Val - Valgina, Cryp - Cryptodontiona, Trich - Trichiina, Os - Osmodermatina, In - Incaina, Cr - Cremastocheilus, Cet(-) Cetoniinae s. str., consisting of Goliathini + Gymnetini + Cetoniini + Schizorhinini + Diplognathini + Cremastocheilini (i.e., without Valgini and Trichiini). Cell values: Clade present $(+)$ or absent $(-)$ on the strict consensus tree followed by bootstrap value, if applicable. Cell color: Black, grey and white for highly supported, moderately supported and unsupported branches, respectively. Column SV/RSV and row RV/RRV indicate Support Value/Relative Support Value for individual clades and Resolution Value/Relative Resolution Value for individual analyses, respectively (for their meaning and calculation see Material and methods).

\begin{tabular}{|c|c|c|c|c|c|c|c|c|c|c|c|c|c|}
\hline Analysis \#\# & SV/RSV & 1 & 2 & 3 & 4 & 5 & 6 & 7 & 8 & 9 & 10 & 11 & 12 \\
\hline Dataset & & & & & & & & & & & & & \\
\hline Ordered/unord. & & & & & & & & & & & & & \\
\hline $\begin{array}{l}\text { Successive } \\
\text { weighting }\end{array}$ & & no & yes & no & yes & no & yes & no & yes & no & yes & no & yes \\
\hline Tree length & & 175 & 342 & 177 & 330 & 239 & 180 & 245 & 191 & 450 & 490 & 460 & 484 \\
\hline $\mathrm{CI} / \mathrm{RI}$ & & $31 / 76$ & $59 / 90$ & $31 / 78$ & $60 / 93$ & $20 / 68$ & $58 / 93$ & $19 / 69$ & $55 / 93$ & $22 / 69$ & $52 / 89$ & $22 / 70$ & $52 / 90$ \\
\hline$\#$ of shortest trees & & $>1484$ & $>1574$ & $>1484$ & $>1581$ & $>1581$ & $>1582$ & $>1582$ & 814 & $>1164$ & $>1579$ & 1 & $>1579$ \\
\hline \multicolumn{14}{|c|}{ Single fully and most consistently resolved topology } \\
\hline Valg & $24 / 100 \%$ & $+/ 98$ & $+/ 99$ & $+/ 99$ & $+/ 99$ & $+/ 96$ & $+/ 96$ & $+/ 96$ & $+/ 94$ & $+/ 99$ & $+/ 100$ & $+/ 99$ & $+/ 99$ \\
\hline Tric & $18 / 75 \%$ & $+/ 85$ & $+/ 85$ & $+/ 85$ & $+/ 85$ & $-/$ na & -158 & $-1<50$ & $+/<50$ & $+/ 86$ & $+/ 88$ & $+/ 66$ & $+/ 86$ \\
\hline Inca & $16 / 67 \%$ & $-/$ na & $-/$ na & $-/$ na & $-/$ na & $+/ 74$ & $+/ 74$ & $+/ 75$ & $+/ 66$ & $+/ 82$ & $+/ 86$ & $+/ 71$ & $+/ 88$ \\
\hline Val+Cryp & $12 / 50 \%$ & $+/ 66$ & $+/ 67$ & $+/ 67$ & $+/ 69$ & $-/$ na & $-/$ na & $-/$ na & $-/$ na & $-/<50$ & $+/ 61$ & $-/ \mathrm{na}$ & $+/ 61$ \\
\hline $\mathrm{Val}+$ & $14 / 58 \%$ & $+/ 63$ & $+/ 76$ & $+/ 76$ & $+/ 78$ & $-/$ na & $-/$ na & $-/$ na & $-/$ na & $+/ 63$ & $+/ 70$ & $-/$ na & $+/ 67$ \\
\hline $\operatorname{Cet}(-$ & $17 /$ & $-/$ na & $-/$ na & -157 & $-/$ na & $+/ 71$ & $+/ 70$ & $+/ 75$ & $+/ 60$ & $+/ 81$ & $+/ 87$ & $+/ 66$ & $+/ 86$ \\
\hline $\operatorname{Cet}(-)$ & $7 / 29 \%$ & $-/$ na & $-/$ na & -159 & $-/$ na & $-/$ na & $-/$ na & $-/$ na & $-/$ na & $+/ 74$ & $-/ 60$ & $+<<50$ & $+/ 77$ \\
\hline $\operatorname{Cet}(-)+\mathrm{Os}$ & $14 / 58 \%$ & $+/ 75$ & $+/ 76$ & $-/ 70$ & -155 & $-/$ na & $-/$ na & $-/$ na & $-/$ na & $+/ 83$ & $+/ 86$ & $+/ 64$ & $+/ 84$ \\
\hline Cet( & & $-/ \mathrm{na}$ & $-/ \mathrm{na}$ & $-/$ na & $-/$ na & $-/$ na & $-/$ na & $-/$ na & $-/$ na & $+/ 70$ & $+/ 74$ & $-<<50$ & $+/ 73$ \\
\hline CETONIIN & $16 / 67 \%$ & $+/ 70$ & $+/ 70$ & $+/ 72$ & $+/ 74$ & $-/$ na & $-/$ na & $-/$ na & $-/$ na & $+/ 82$ & $+/ 86$ & $+/ 75$ & $+/ 89$ \\
\hline \multirow[t]{2}{*}{ RV/RRV } & & $12 / 60 \%$ & $12 / 60 \%$ & $13 / 65 \%$ & & $6 / 30 \%$ & $7 / 35 \%$ & $6 / 30 \%$ & $7 / 35 \%$ & $18 / 90 \%$ & $19 / 95 \%$ & $13 / 65 \%$ & $20 / 100 \%$ \\
\hline & \multicolumn{9}{|c|}{ Alternative grouping } & $-/ \mathrm{na}$ & -/na & $-/ \mathrm{na}$ & -/na \\
\hline
\end{tabular}

invasive alien species such as the Japanese beetle, Popillia japonica (Newman, 1841).

\section{MATERIAL AND METHODS}

\section{Sources, identification and handling of Coelocorynus larvae}

The field-collected Cameroonian larvae were identified as belonging to Coelocorynus based on the following considerations: (1) they were found together with teneral adults of this species in the same log, which was not co-inhabited by any other Scarabaeoidea larvae or adults, and (2) they agree morphologically with the larvae of $C$. opacicauda Arrow, 1926 illustrated in Grebennikov \& Scholtz (2004) and Scholtz \& Grebennikov (2005), as well as with the larvae identified as such in the National History Museum, London (NHML; see below).

Besides $C$. desfontainei, one author (PŠ) found in the NHML collection one vial containing one third-instar and four secondinstar Cetoniinae larvae labelled "Coelocorynus opacicauda (Arrow) Aberdare Mts, (Gedye)" and subsequently an adult of C. opacicauda labelled "W. Aberdares 10-11,000 ft, Now 1934 A.J.F. Gedye". Comparison of the larvae with those collected in Cameroon revealed an overall similarity and presumed congenerity.

Morphological observations and measurements were carried out using an Olympus SZX9 stereomicroscope and Olympus BX 40 light microscope, both equipped with Olympus Camedia 5060 digital cameras. Mouthparts were dissected and mounted on slides in Liquide de Swan. Drawings were made of photographs. Larval habitus images were produced on a flatbed HPScanjet 5530 scanner. The Helicon Focus programme was used to combine several photographs of adults into a single deepfocus image. The brightness and/or contrast of all pictures have been slightly enhanced in Adobe Photoshop.

Material is deposited in the Canadian National Collection of Insects, Arachnids and Nematodes (CNCI), the B.D. Gill collection $(C$. desfontainei), and in the NHML (C. opacicauda). The morphological terminology used in the present study is adopted from Böving (1936), Ritcher (1966), Lawrence (1991) and Micó et al. (2001).

\section{Morphological datasets and analytical strategy}

Eighty one morphological characters were selected for the analysis; the majority were recently explained and illustrated by Micó et al. (2008). New characters were added and some were re-defined; full character descriptions, state definitions and optimization statistics are given in the Appendix. The combined larval and adult morphological matrix included 60 terminals and 81 characters (Table 2). The tree was rooted using a single representative of the family Trogidae. Characters 1-43 are of larval morphology and 44-81 of adult morphology. No polymorphic characters are present in the matrix. Three larval characters $(5$, $27,34)$ are parsimony uninformative and were not included in the analysis. Eleven multi-state characters $(7,11,13,16,25,30$, $37,52,54,67,77)$ were analysed as being either ordered (analyses 3, 4, 7, 8, 11, 12; Table 1) or unordered (analyses 1, 2, $5,6,9,10$; Table 1); all other multi-state characters were treated as unordered in all analyses. We analysed three separate morphological datasets: Larval (characters 1-43), adult (characters 44-81) and combined (characters 1-81), using for each four possible combinations of ordering and successive weighting 
TABLE 2. Matrix of 60 taxa and 81 larval and adult characters used in phylogenetic analysis of Cetoniinae.

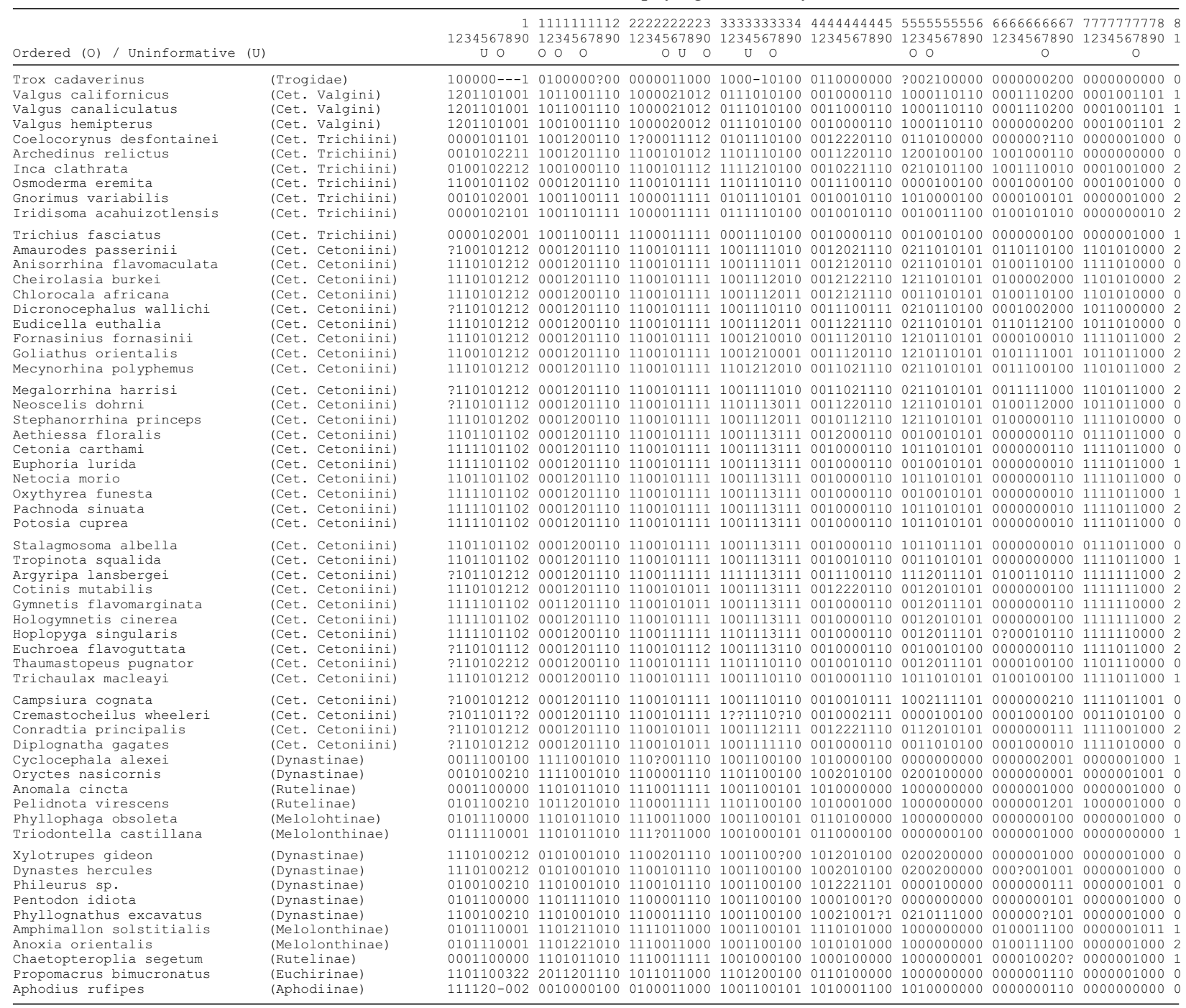

(Farris, 1969) parameters (Table 1). In total, 12 separate analyses were completed and are summarized in Table 1. Hennig86 (Farris, 1988) searched for the shortest (= most parsimonious) trees (heuristic search; commands " $m$ h" and "bb*") and then performed successive approximations (Farris, 1969; executed by a string of commands "xs w", "mh*" and "bb*" repeated in cycles until the tree statistics stabilised). Branch support was assessed using Nona 2.0 (Goloboff, 1999) through bootstrapping 1000 randomly generated trees. Winclada (Nixon, 2002) was used as a shell program to communicate with Nona and to visualise the trees.

\section{Relative Support Value (RSV) and Relative Resolution Value (RRV)}

To make an unambiguous judgement on the strength of support for each of the 10 clades highlighted in Table 1 and to compare the capacity of each of the 12 morphological analyses to consistently resolve these clades, we used the recently introduced statistical measures "Relative Support Value" (RSV) and "Relative Resolution Value" (RRV), respectively (Grebennikov $\&$ Newton, 2009). They were calculated as a ratio of obtained Support Value (SV) for clades and Resolution Values (RV) for analyses to their possible absolute maxima (see below), respectively. Obtained SV and RV were calculated as sum of horizontal (SV) or vertical (RV) individual cell scores varying from 0 (clade unsupported, i.e., absent on the strict consensus tree and bootstrap $<50 \%$; white cell in Table 1) through 1 (clade moder- ately supported, i.e., present on the strict consensus tree and bootstrap $<50 \%$ OR absent on strict consensus tree, but bootstrap equal or $>50 \%$; grey cell in Table 1) to 2 (clade strongly supported, i.e. present on the strict consensus tree and bootstrap equal or $>50 \%$; black cell in Table 1). Maximum possible values for SV and RV (Table 1) for 12 analyses focusing on 10 clades, were 24 and 20, respectively. Maximum possible RSV of $100 \%$, as observed for Valgina (Table 1), indicates that this clade was strongly supported by all 12 analyses, while the lowest RSV of $25 \%$, as observed for the clade of Cetoniina s. str. + Osmodermatinae + Incaina (Table 1), indicates that it was recovered only a few times. Maximum possible RRV of $100 \%$, as observed for analysis 12 (Table 1), indicates that this analysis was capable of resolving all 10 clades and each clade was strongly supported, while the lowest observed RRV of $30 \%$, as recorded for analyses 5 and 7 (Table 1), indicates that they were only partly consistent with the most supported and fully resolved topology (Fig. 25).

\section{RESULTS}

\section{Generic description of third-instar Coelocorynus larvae}

A typical C-shaped grub (Figs 3, 4); with only a few long setae; abdomen 10-segmented, segments subequal in 

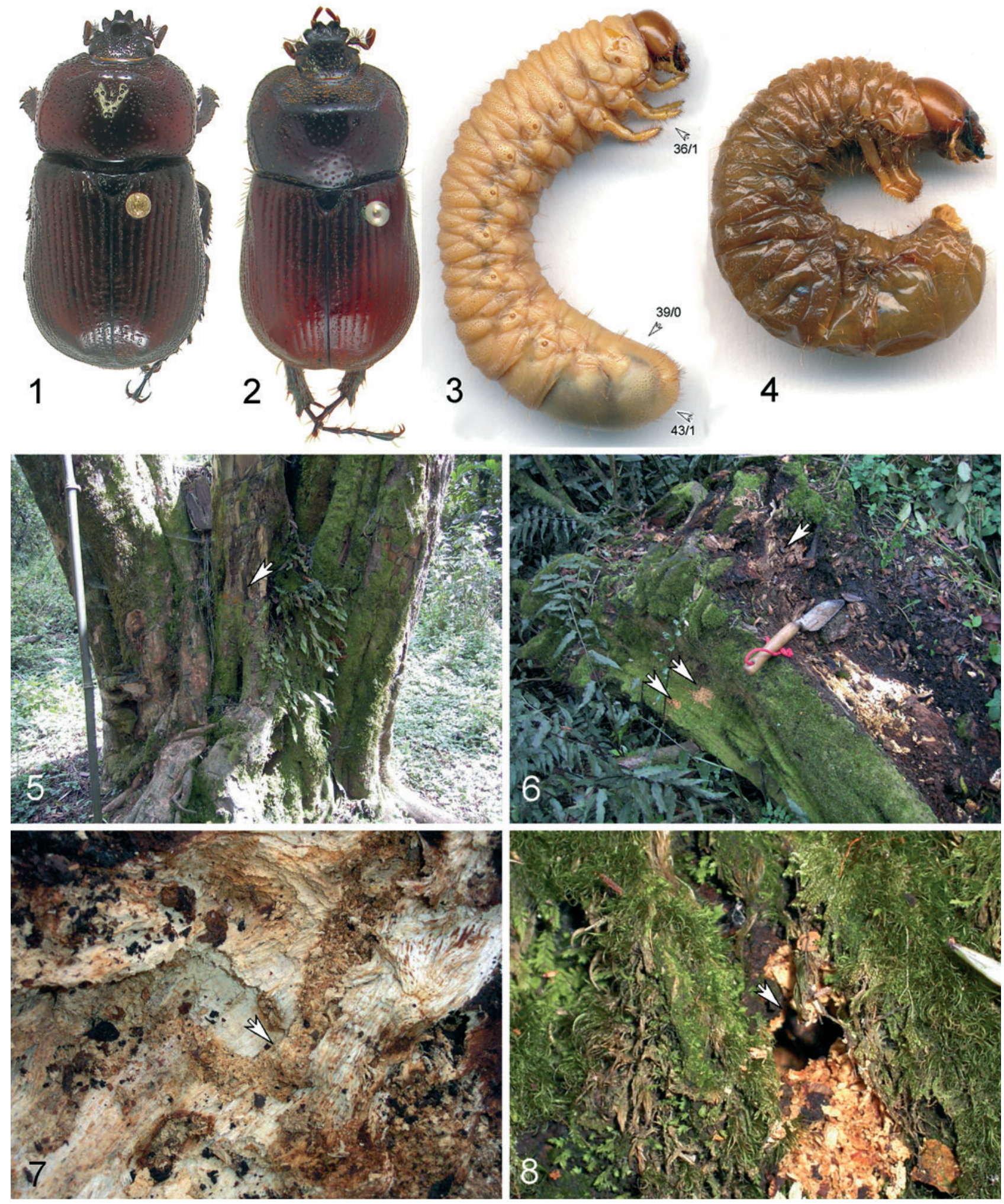

Figs 1-8. Habitus of Coelocorynus adults $(1,2)$ and larvae $(3,4)$ and the habitat of Coelocorynus in the forest at $2800 \mathrm{~m}$ on Mt. Oku above Elak village, Northwest Province, Cameroon (5-8). 1,3-C. desfontainei; 2, $4-C$. opacicauda; 5 - standing tree with arrow pointing to location where an adult male was removed from a $1 \mathrm{~cm}$ diameter gallery; 6 - partially rotten trunk on ground with larvae and newly emerged adults (upper arrow pointing to an adult beetle; two lower arrows indicating frass below two adult exit holes); 7 - feeding burrows of larvae in rotten wood backfilled with frass (indicated by arrow); 8 - close-up of adult exit hole, illustrated in Fig. 6 (indicated by arrow), with frass below. Arrows with small numbers in Fig. 3 point to the character states described in Appendix. 

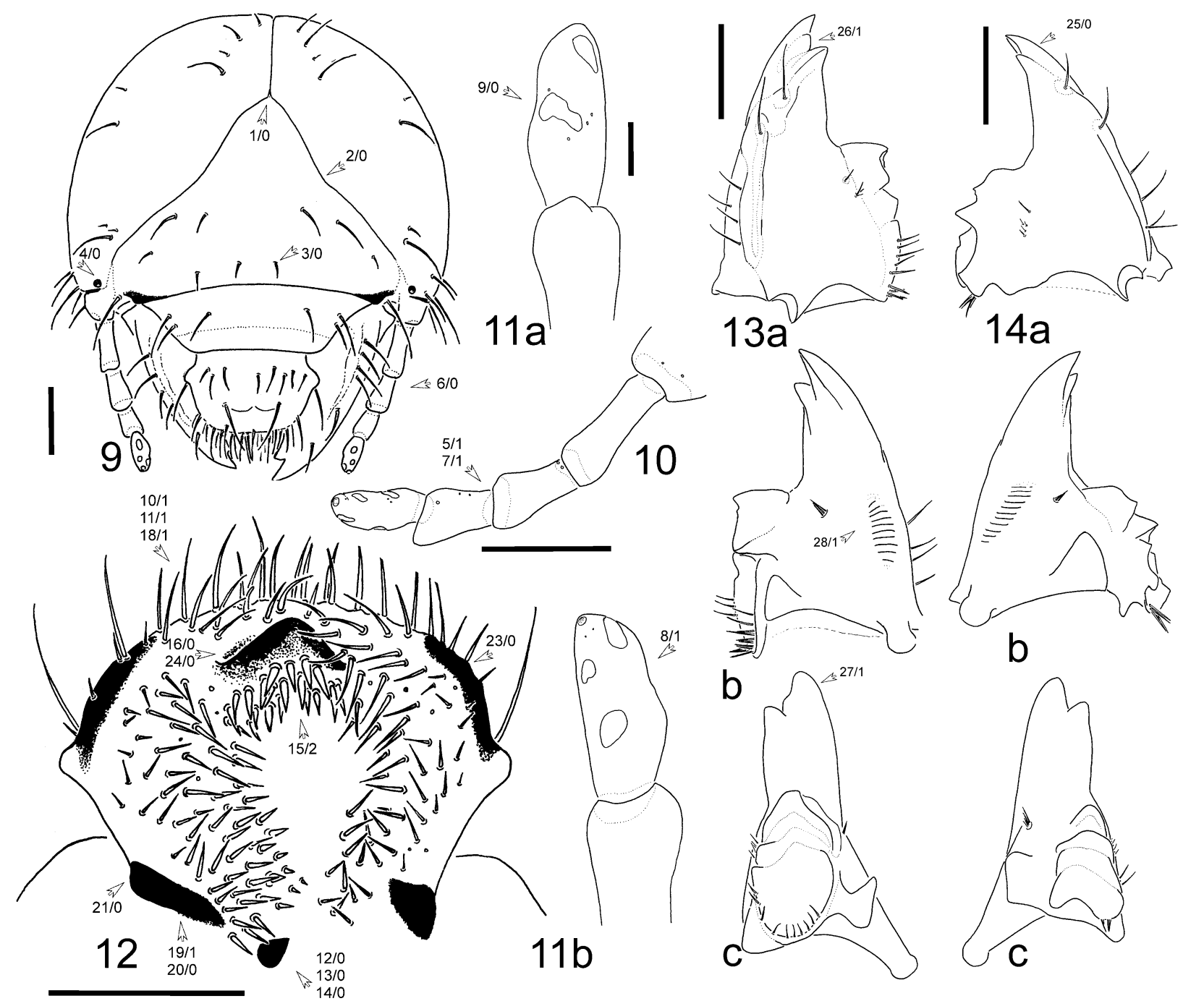

Figs 9-14. Coelocorynus desfontainei, third-instar larva. 9 - head capsule; 10 - right antenna, lateral view; 11 - ultimate antennomere of right antenna, ventral view (a) and dorsal view (b); 12 - epipharynx; 13 - left mandible, dorsal (a), ventral (b) and medial (c) views; 14 - right mandible, dorsal (a), ventral (b) and medial (c) views. Scale bars: 9, 10, 12-14-1 mm; 11a,b - 0.2 mm. Arrows with small numbers point to the character states described in Appendix.

size except for slightly prolonged segments IX and $\mathrm{X}$; body length 46-58 $\mathrm{mm}$.

Head as in Figs 9 and 21; maximum width 5.6-5.8 mm; head surface with fine microsculpture, yellowish brown; antennifer, postclypeus and labrum brown; chaetotaxy as figured; frontal sutures evenly sinuate to lyriform; dorsal endocarina not protruding further than anterior part of epicranial suture; clypeus trapezoidal, anteclypeus membranous, postclypeus heavily sclerotized with 2 exterior and 1 anterior setae on each side; frontoclypeal suture distinct along entire length; single pigmented or unpigmented stemma present on each side of head.

Antennae (Figs 10-11, 23-24) with 4 subequal antennomeres devoid of setae; antennomere I slightly longer than others; antennomere III with ventral and apically protruding portion bearing sensory area on its dorsal surface; antennomere IV with 2 ventral and 3 dorsal sensory spots and a small apical field with a few minute sensilla.

Labrum nearly symmetrical; anterior margin convex, with numerous setae; middle of lateral margin with dis- tinctly projecting tubercle; dorsal surface with 2 transverse rows of setae; posterior row with $8-13$ setae and 2 long setae beneath lateral tubercle; anterior row with 1 paramedian and 1 lateral seta on each side.

Epipharynx (Figs 12, 22) with well sclerotized and prominent haptomeral process bearing apical field of pore-like sensilla and 3-4 lines of stout, spine-like setae posteriorly; acroparia with about 30 long setae; clithra and epizygum absent; lateral margin of epipharynx with strong medial tubercle and heavily sclerotised anteriorly; acanthoparia with 4-6 irregularly located setae; setae on chaetoparia located in 5-6 longitudinal rows, setae in medial rows stout, almost spine-like; plegmata and proplegmata absent; pedium moderately broad; dexiotorma bar-like, longer than laeotorma, right pternotorma absent; laeotorma triangular with posterior pternotorma; haptolachus with sensory cone and $4-5$ pores, sclerotised plate absent; crepis faintly sclerotised, indistinct.

Mandibles (Figs 13-14) prominent; right with 2, left with 3 scissorial teeth; scrobis with 3-5 setae; dorsal 

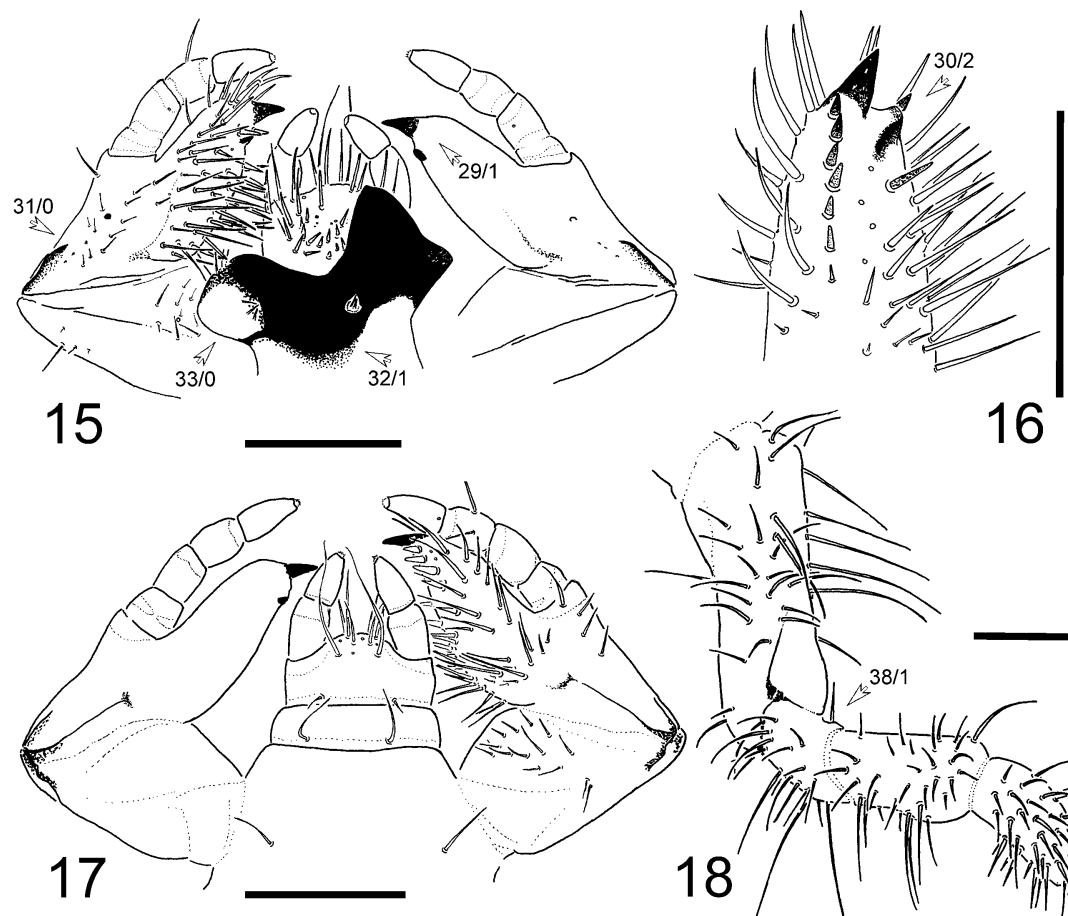

16
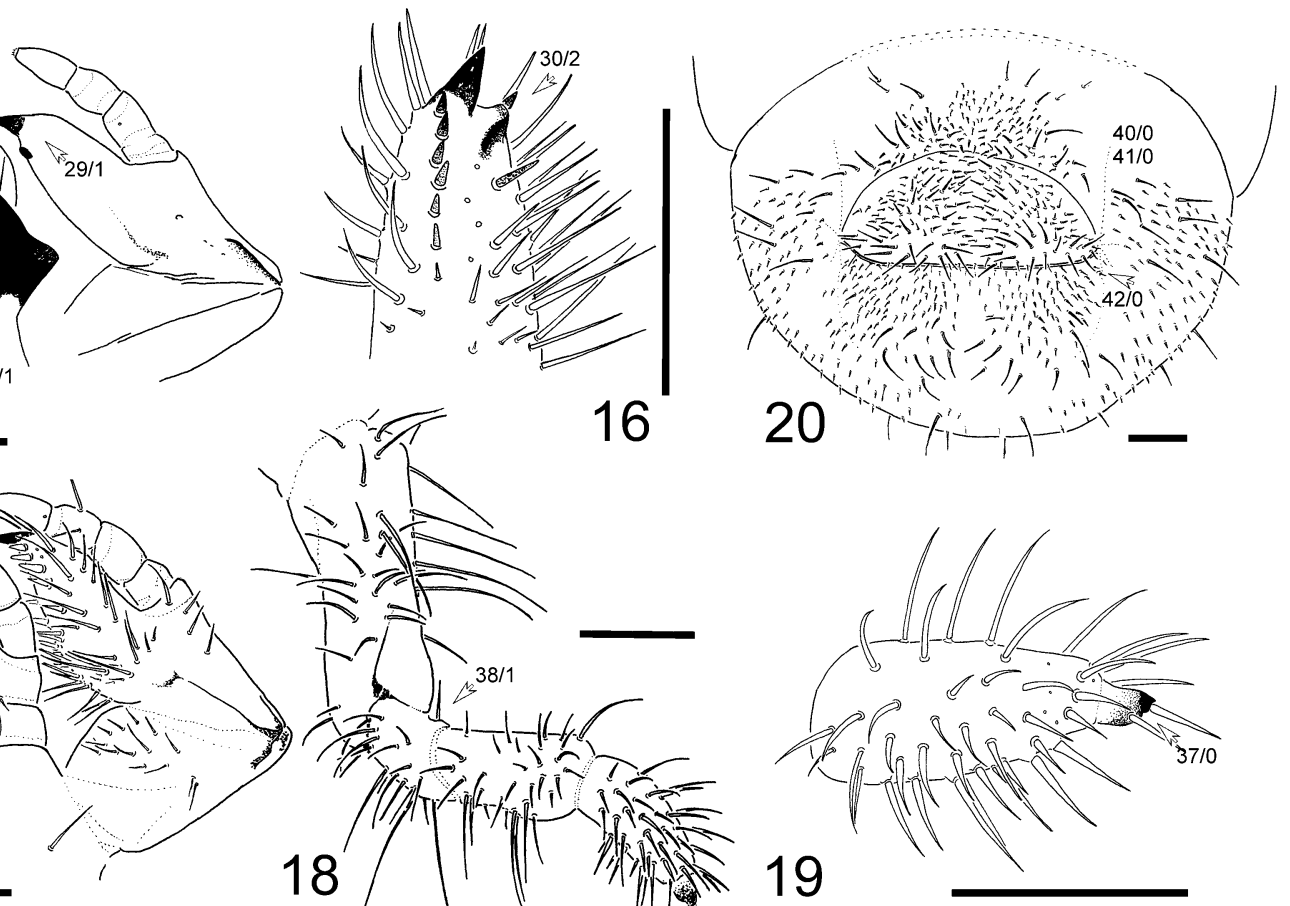

Figs 15-20. Coelocorynus desfontainei, third-instar larva. 15 - labium and maxillae, dorsal view; 16 - apex of left maxilla, medioventral view; 17 - labium and maxillae, ventral view; 18 - right metathoracic leg; 19 - claw of right metathoracic leg; 20 - last abdominal segment, ventral view. Scale bars: $1 \mathrm{~mm}$. Arrows with small numbers point at character states as described in Appendix.

carina present; dorso- and ventro-molar setae present, ventro-molar setae aggregated to form a rim; ventral stridulatory area present on both mandibles, with about 10-15 transverse ridges and with apical asperities less distinct; molar lobes of both mandibles with sharp projections; posterior margin of calyx in medial aspect concave on right mandible, flattened and convex on left; right and left mandible with 10 and 12 setae on each brustia, respectively.

Maxilla (Figs 15-17) with several hair-like setae on cardo and labacobaria dorsally; stipes with 10-11 faint setae dorsally; maxillary stridulatory area much reduced posteriorly, with 2-6 small or minute recurved spines and one conical process dorsally on middle of basal part of stipes; galea and lacinia (Fig. 16) fused forming mala; galeo-lacinial suture absent; galeal uncus falcate; lacinial unci reduced with 2 apical stout setae and preapical sclerotized tubercle; mala with numerous long stout setae dorsally and with a longitudinal row of 4-7 spine-like setae and about 20 hair-like setae ventrally; maxillary palpus with 4 palpomeres and segment-like palpifer.

Hypopharynx with hypopharyngeal sclerome (Fig. 15) asymmetrical, with strong protruding truncate process and a few seta-like tegumentary expansions medio-posterior to the process; left lateral lobe membranous, with 3-4 seta-like tegumentary expansions; glossa with about 10 short stout setae in medio-proximal area and about 20 long setae and 10 pores on distal half; labial palpi twojointed.
Thorax with all legs (Figs 18-19) subequal and with similar tarsal claws (Fig. 19); claws cylindrical, rounded at apex, with 2 apical setae and minute tip; prothoracic sclerite present; mesothoracic spiracle with C-shaped respiratory plate; distance between lobes of respiratory plate about half of, or equal to, maximum diameter of respiratory plate; metathoracic spiracles present, highly reduced and non-functional; each dorsal sub-lobe with 3-5 rows of short setae, posterior row with short and few long setae; venter with about 10 long setae on each segment.

Abdomen 10-segmented; segments IX and X separate, slightly longer than others and not distinctly thickened; chaetotaxy on abdominal segments I-VII as on thorax, chaetotaxy on segments VIII-IX much reduced; raster (Fig. 20) without clearly distinguishable septula, palida and hamate; anal slit transverse, dorsal anal lobe with numerous small spiny setae and few long setae in 2 rows; lower anal lip with numerous short and long setae; abdominal spiracles I and VIII largest, all others smaller and subequal in size.

\section{Diagnostic characters of third-instar Coelcorynus larvae}

Coelocorynus desfontainei Antoine, 1999 (Figs 3, 7, 9-20). Maximum width of head capsule $5.6 \mathrm{~mm}(\mathrm{n}=1)$; stemma on each side of head pigmented; apical half of ultimate antennomere in lateral view almost cylindrical, without protrusions; epipharynx with gymnoparia indistinct or absent, right chaetoparia with 65-71 and left with 51-53 setae; ventral stridulatory area on mandibles with $10-12$ ridges; maxillary stridulatory area with $2-3$ small 


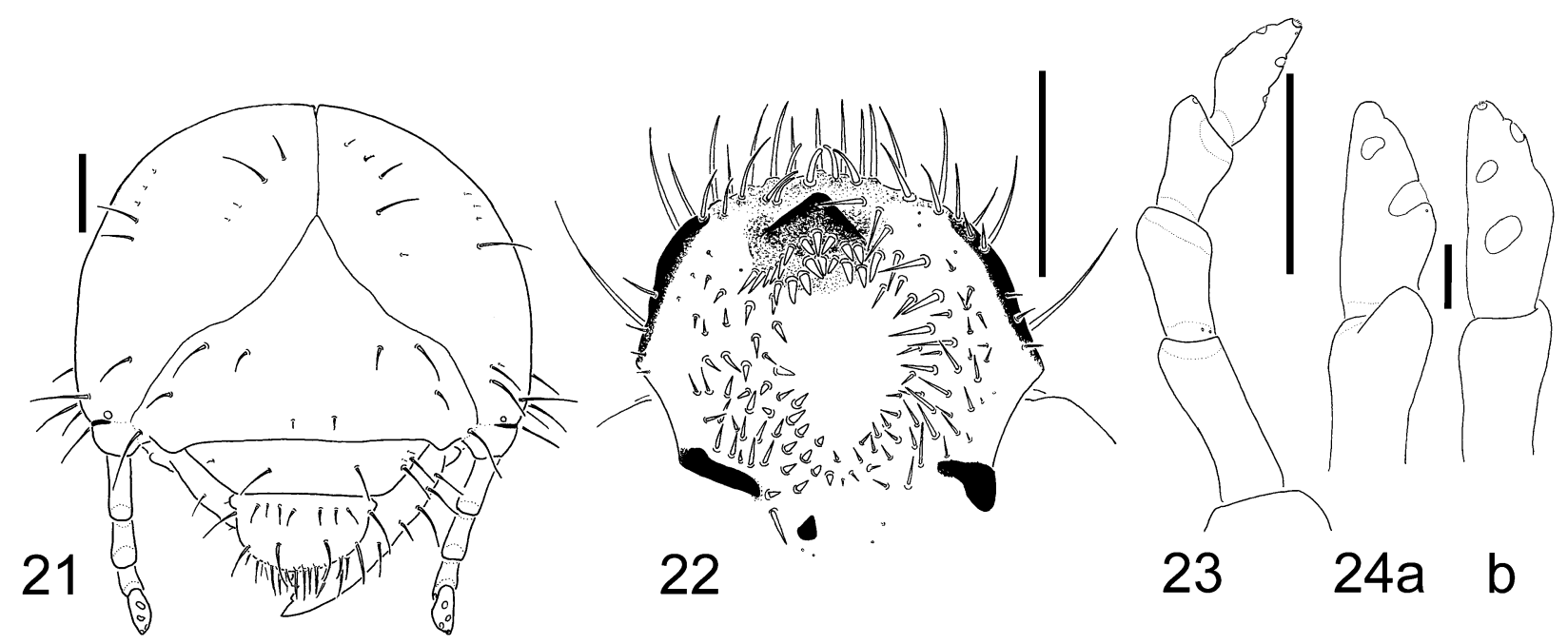

Figs 21-24. Coelocorynus opacicauda, third-instar larva. 21 - head capsule; 22 - epipharynx; 23 - right antenna, lateral view; 24 - right ultimate antennomere, ventral (a) and dorsal (b) views. Scale bars: $21-23-1 \mathrm{~mm} ; 24-0.2 \mathrm{~mm}$.

recurved spines posteriorly; greatest length of mesothoracic spiracles $0.625 \mathrm{~mm}$ and distance between lobes subequal to, or as long as, spiracular plate.

Coelocorynus opacicauda Arrow, 1926 (Figs 4, 21-24). Maximum width of head capsule $5.8 \mathrm{~mm}(\mathrm{n}=1)$; stemma on each side of head unpigmented; apical half of ultimate antennomere in lateral view more or less conical, with protrusion bearing apical sensory area; ephipharynx with gymnoparia more or less developed, each chaetoparia with about 50 setae; ventral stridulatory area on mandible with 13-15 distinct ridges; maxillary stridulatory area with 5-6 recurved spines posteriorly; greatest length of mesothoracic spiracles $0.600 \mathrm{~mm}$ and distance between lobes subequal to half the length of spiracular plate.

\section{Biology of Coelocorynus}

Larvae of $C$. desfontainei were recorded by B.D. Gill in early May 2006 in standing and fallen dead wood at an altitude of around 2,800 $\mathrm{m}$ on Mt. Oku, Northwest Province, Cameroon. The first adult was collected inside dead wood of a large moss-covered standing tree (Fig. 5). A small hole on the outside of the trunk (roughly $1 \mathrm{~cm}$ diameter) had an accumulation of frass below the hole. The hole was excavated and a male beetle found. Several days later a partially rotten tree trunk lying on the ground nearby was observed with two holes and a telltale accumulation of granular frass (Fig. 6-8) on the moss and lichens below the holes. These holes were excavated and a single teneral female was found in the larger of the two galleries. The rest of the log was chopped open to expose one more adult, plus the remains of several adults that had died in their pupal chambers. Several larvae were found feeding in the soft rotten wood. The larval feeding galleries meandered through the rotten wood and were densely packed with frass (Fig. 7). All the adults collected had recently emerged as they had no obvious signs of wear on their legs or clypeus. The accumulation of granular frass below the holes indicated they had excavated their emergence tunnels but then remained in their tunnels, at least during the day. No other scarab larvae or adults were found in rotting wood at this altitude, although dynastine and cetoniine larvae were found in rotting wood on Mt. Oku below $2000 \mathrm{~m}$.

Another observation on Coelocorynus biology was made by VVG in October 2001 on the western slope of Mt. Kenya at the meteorological station on the Naro Moru Route (altitude $3050 \mathrm{~m}$ ). Five live adults of C. opacicauda Arrow, 1926, along with some unhatched eggs, were excavated at about chest height from under the bark of a dead standing tree at the upper edge of the montane forest. The eggs were kept in a container and at least two first-instar larvae were obtained. These larvae were illustrated and scored for a phylogenetic analysis of Scarabaeoidea (Grebennikov \& Scholtz, 2004; Scholtz \& Grebennikov, 2005).

\section{Results of the cladistic analysis}

The results of 12 parsimony analyses of morphological data are summarized in Table 1 . The most consistently resolved topology of the Cetoniinae basal branching events presented in Fig. 25 represents a majority rule consensus tree obtained from the strict consensus and bootstrap trees of each of 12 analyses. Relative support values are plotted against each clade in Fig. 25. To facilitate further discussion, all 12 analyses are grouped into three sets based on the source of data: larval (analyses 1-4), adult (analyses 5-8), and combined (analyses 9-12); the former two are also termed "partial". For convenience, Cetoniinae s. str. is defined as Cetoniinae without Valgini and Trichiini.

\section{DISCUSSION}

\section{Position of Coelocorynus and re-evaluation of Micó et al's (2008) hypothesis on Cetoniinae phylogeny}

We hypothesise that the genus Coelocorynus is a sistergroup of the tribe Valgini, represented in our analysis by three Valgus species. Other branching events in the monophyletic Cetoniinae revealed by our analysis (Table 


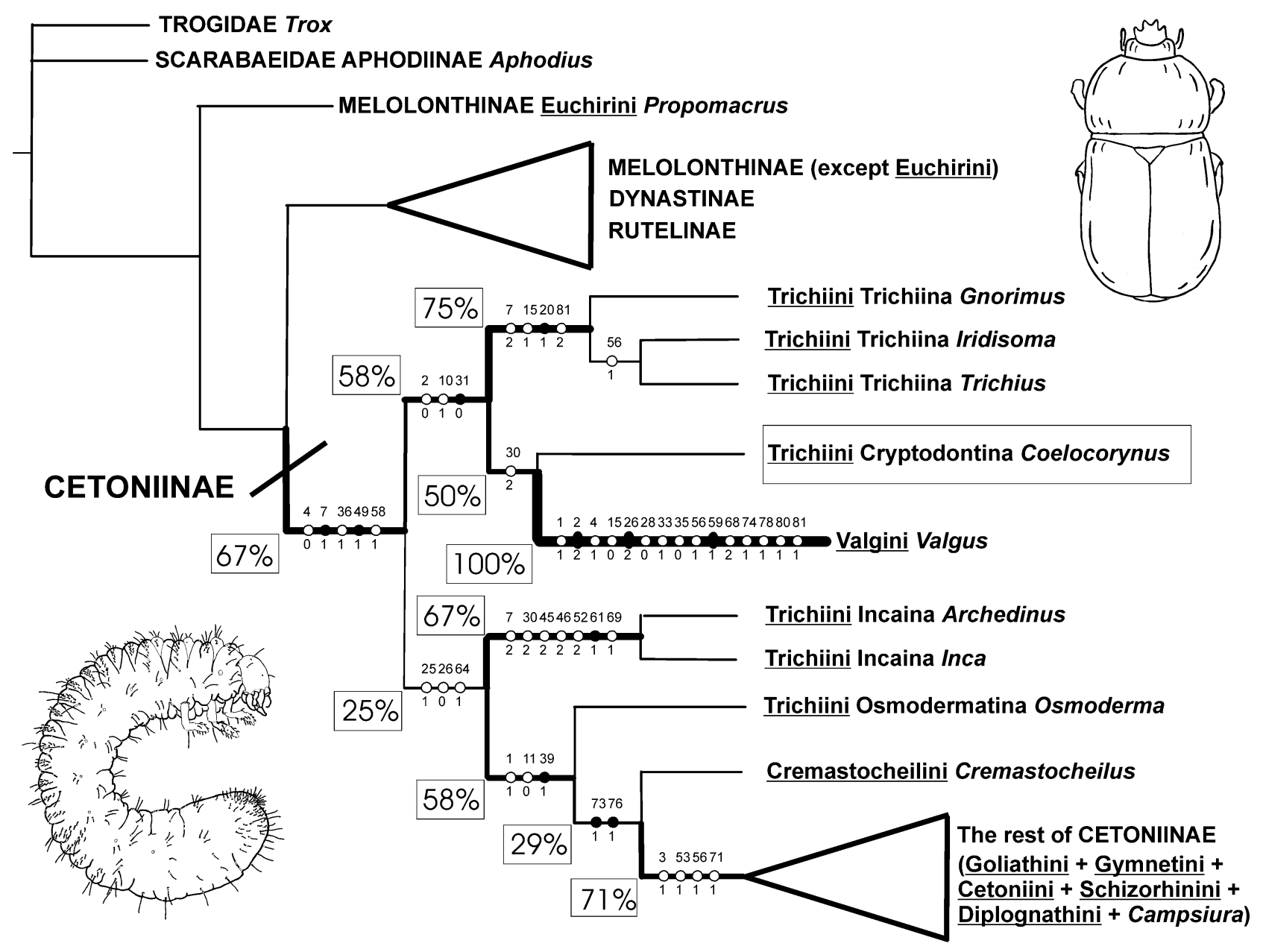

Fig. 25. Consensus phylogeny of the Cetoniinae based on combined analyses of data on larval and adult morphology with some characters ordered and all characters successively weighted (analysis 12). Unambiguously optimized characters are superimposed on internodes; character numbers are above circles; numbers of newly acquired apomorphic character states are below circles; black circles indicate unique evolutionary events; white circles indicate parallelisms or reversals. Boxed Relative Support Values (expressed in percent) are proportional to the width of internodes and reflect the overall relative confidence in the hypothesis that a clade is monophyleyic. An adult and a larva of Coelocorynus are illustrated by outline drawings; position of this taxon is boxed on the cladogram.

1 and Fig. 25) fully agree with those proposed by Micó et al. (2008). This is not surprising, because our matrix relied heavily on their data for character selection and taxon sampling. We deviated from these authors however, in the analytical methodology and therefore, in the resulting degree of confidence associated with a monophyly hypothesis for each resolved clade. Instead of using bootstrap or Bremer values suitable to represent clade stability in an individual analysis, we calculated "Relative Support Value" (RSV; as explained in Material and methods), which represents clade stability in multiple analyses. Among the most parsimonious clades depicted in Fig. 25, the weakest were Cetoniinae s. str. and Cetoniinae s. str. + Osmodermatina + Incaina with RSV of $29 \%$ and $25 \%$, respectively. The most strongly supported clade is Valgini with a RSV of $100 \%$. This high support is considered a sampling artefact because this relatively diverse tribe has more than 30 genera and was represented in our analyses by three congeneric Valgus species. All remaining seven clades highlighted in our analyses have intermediate RSV ranging from 50\% (Valgini + Crypto- dontina) to $75 \%$ (monophyly of the three Trichiina genera).

\section{Relative contribution of larval versus adult characters}

Availability of larval and adult characters scored for the same set of terminals permits a comparison of the ability of individual partial datasets to resolve clades in a way consistent with those obtained from the combined dataset. The results indicate that, with the single exception of Valgini (or, rather, the genus Valgus represented in the analyses by three species), a clade consistently supported by one partial dataset becomes invariably and consistently rejected by the other. This phenomenon is illustrated by the shading of individual cells in Table 1, with black indicating strong support for a clade, and white indicating lack of support. Contrary to the topologies obtained from the combined and adult analyses (columns 9-12, 5-8, respectively), those based on larval characters (columns 1-4) were not able to determine whether two clades were monophyletic: Incaina and Cetoniinae s. str. without Cremastocheilus. Conversely, adult analyses (\#5-8) were 
plagued by recovering a presumably artificial group of Valgini + Osmodermatina + Cremastocheilus (the lowest row of Table 1), thus rejecting three monophyletic groups consistently recovered in the larval and combined analyses (columns 1-4 and 9-12, respectively): Valgini + Cryptodontina; Valgini + Cryptodontina + Trichiina; and Cetoniina s. str. + Osmodermatina + Incaina. Adult analyses also did not support monophyly of either Trichiina or Cetoniinae. Two other clades, Cetoniinae s. str. and Cetoniinae s. str. + Osmodermatina + Incaina, recovered in the combined analyses as most parsimonious, were not detected in the partial analyses. The overall contribution of each of the 12 analyses to resolving the tree in a manner consistent with the most parsimonious hypothesis is measured by "Relative Resolution Value" (Table 1). Comparison of these values for the three datasets suggests that adult-based topologies (value 30-35\%) were only half as good as those based on larvae (value 55-65\%; this conclusion was also reached by Micó et al., 2008, without, however, measuring the RRV), while combined analyses provided the most resolved and, simultaneously, the most parsimonious trees (value 65-100\%). These results highlight the importance of bringing at least two independent character sets into the analysis to achieve statistically sound results, which, hopefully, reflect the true evolutionary history of the group.

\section{Direction of further research}

Monophyly of Valgini will remain uncertain until members of the termitophilous subtribe Microvalgina, and their completely unknown larvae, are included in the analysis. Besides Microvalgina, Platygeniina is the only Cetoniinae subtribe outside of Cetoniinae s. str. not represented in our analysis. Although third-instar larvae of Platygenia barbata (Afzel, 1817) have been collected from oil palm in Nigeria and subsequently described (Jerath \& Unny, 1965), the description is not detailed enough to permit character scoring. The non-monophyletic "tribe" Trichiini, with (a) the Valgini and (b) the rest of Cetoniinae derived from within it, requires a new set of tribes and subtribes to adequately reflect the new phylogenetic findings (also proposed, although not implemented, by Smith et al., 2006).

ACKNOWLEDGMENTS. This project was supported by the Charles University Grant Agency (grant \#GAUK 119207) and by the Ministry of Education of the Czech Republic (grant \#MŠMT ČR-0021620828) to PŠ. Canadian co-authors BDG and VVG want to acknowledge the hospitality of their Cameroonian hosts E.C. Suh, N. Godlove A., G. Chuyong (all of University of Buea) and P. Tamanji (Université de Yaoundé II). Alexander von Humboldt Foundation (www.avh.de) is acknowledged for creating a World network of former Fellows, which brought BDG and VVG in touch with the colleagues in Cameroon thus leading to successful completion of their trip. Fieldwork in Cameroon for VVG was supported by a research grant provided by E. Hintelmann (Munich, Germany) through a scientific foundation she has established at the Zoologische Staatssammlung München (http://www.zsm.mwn.de/events/wiss_preise.htm) in memory of her late husband R.J.H. Hintelmann. H. Laubvogel and H.-U. Raake (Universitätsbibliothek, Museum für Naturkunde, Humboldt-Universität zu Berlin, Germany) helped locate the difficult-to-find 1909 Kolbe paper. K. McLachlan-Hamilton (Canadian Food Inspection Agency, Ottawa) reviewed this MS prior to submission.

\section{REFERENCES}

Antorne P. 1999: Quelques espèces nouvelles ou peu connues de la famille des Cetoniidae (Coleoptera) - VII. Entomol. Afr. 4: $2-16$.

Antoine P. 2003: Révision du genre Coelocorynus Kolbe (Coleoptera, Cetoniidae, Trichiinae). Coléoptères 9: 127-150.

Böving A.G. 1936: Description of the larva of Plectris aliena Chapin and explanation of new terms applied to the epipharynx and raster. Proc. Entomol. Soc. Wash. 38: 169-185.

FARRIS J.S. 1969: A successive approximation approach to character weighting. Syst. Zool. 18: 374-385.

Farris J.S. 1988: Hennig86. Published by the author, Port Jefferson Station, NY, USA.

Goloboff P. 1999: NONA, Version 2. Published by the author, Tucumán, Argentina.

GrebenNikov V.V. \& Newton A.F. 2009: Good-bye Scydmaenidae, or why the ant-like stone beetles should become megadiverse Staphylinidae sensu latissimo (Coleoptera). Eur. J. Entomol. 106: in press.

Grebennikov V.V. \& Scholtz C.H. 2004: The basal phylogeny of Scarabaeoidea (Insecta: Coleoptera) inferred from larval morphology. Invertebr. Syst. 18: 321-348.

JeRATH M.L. \& UnNY K.L. 1965: Larvae of six genera of Cetoniinae from Eastern Nigeria (Coleoptera: Scarabaeidae). Coleopt. Bull. 19: 59-64.

KolBe H. 1909: Über die Cryptodontinen, ein verbindendes Glied zwischen den Dynastiden und den melitophilen Lamellicornien. Entomol. Rdsch. 26: 81-83.

KRIKKEN J. 1984: A new key to the suprageneric taxa in the beetle family Cetoniidae, with annotated list of the known genera. Zool. Verh. 210: 1-77.

LAWRENCE J.F. 1991: Order Coleoptera (general discussion, family key, various family treatments). In Stehr F.W. (ed.): Immature Insects. Vol. II. Kendal/Hunt, Dubuque, Iowa, pp. 144-658.

Micó E., Verdú J.R. \& Galante E. 2001: Larval morphology of some Anisoplinini grain beetles with a key to their larvae (Coleoptera: Scarabaeoidea: Rutelidae: Anomalinae). Eur. J. Entomol. 98: 311-320.

Micó E., Morón M.A., Š́́́pek P. \& Galante E. 2008: Larval morphology enhances phylogenetic reconstruction in Cetoniidae (Coleoptera: Scarabaeoidea) and allows the interpretation of the evolution of larval feeding habits. Syst. Entomol. 33: 128-144.

Nixon K.C. 2002: WinClada, Version 1.0000. Published by the author, Ithaca, NY.

Ritcher P.O. 1966: White Grubs and their Allies: A Study of North American Scarabaeoid Larvae. Oregon State University Press, Corvallis, 219 pp.

Scholtz C.H. \& GrebenNikov V.V. 2005: Scarabaeiformia Crowson, 1960. In Beutel R.G. \& Leschen R.A.B. (eds): Handbook of Zoology. A Natural History of the Phyla of the Animal Kingdom. Vol. 4 Arthropoda: Insecta, Part 38. Coleoptera, Beetles Vol. 1: Morphology and Systematics (Archostemata, Adephaga, Myxophaga, Polyhaga partim.). Walter de Gruyter, Berlin, pp. 345-425.

Sмiтн A.B.T. 2006: A review of the family-group names for the superfamily Scarabaeoidea (Coleoptera) with corrections to nomenclature and a current classification. Coleopt. Soc. Monogr. 5: 144-204. 
Smith A.B.T., Hawks D.C. \& Heraty J.M. 2006: An overview of the classification and evolution of the major scarab beetle clades (Coleoptera: Scarabaeoidea) based on preliminary molecular analyses. Coleopt. Soc. Monogr. 5: 35-46.

Received April 11, 2008; revised and accepted November 21, 2008

APPENDIX. List of 81 morphological characters used in the analysis.

The abbreviation "MMŠG" followed by a number indicates the character used by Micó et al. (2008); abbreviation "mod." indicates whether it was significantly re-worded compared to the original source. Character statistics: ci - consistency index; ri - retention index; SW - successive weighting on scale 0 to 10. Character state optimization refers only to the characters illustrated in Fig. 25 (i.e., informative at basal splits within the ingroup and excluding autapomorphies, also excluding autapomorphies for the highly supported Valgini, represented only by three Valgus species).

Larvae

1. Epicranial suture [MMS̆G: 1]: not extending between frontal suture $=0$ (Fig. 9); extending between frontal suture $=1$. State 1 is a synapomorphy for Osmodermatina + Cetoniinae s. str. (with a parallelism in Valgini and numerous cases of ambiguity inside Cetoniinae s. str.). $\mathrm{ci}=20 ; \mathrm{ri}=75 ; \mathrm{SW}=1$.

2. Frontal suture [MMŠG: 2]: not sinuate or smoothly sinuate $=0$ (Fig. 9); bisinuate $($ concave $)=1$; sinuate $($ convex $)=2$. State 0 is a synapomorphy for Trichiina + Cryptodontina + Valgini (with a subsequent reversal in Valgini and parallelism in Incaina: Archedinus). ci=28; $\mathrm{ri}=54 ; \mathrm{SW}=1$.

3. Anterior frontal setae [MMS̆G: 3]: present $=0$ (Fig. 9); absent or reduced $=1$. State 1 is a synapomorphy for Cetoniinae s. str. except Cremastocheilus (with numerous parallelisms and reversals both inside and outside this clade). $\mathrm{ci}=6 ; \mathrm{ri}=48 ; \mathrm{SW}=0$.

4. Stemmata [MMŠG: 4]: present $=0$ (Fig. 9); absent $=1$. State 0 is a synapomorphy for Cetoniinae (with a subsequent reversal in Valgini, Cremastocheilus and some other Cetoniini s. str.). $\mathrm{ci}=14 ; \mathrm{ri}=77 ; \mathrm{SW}=1$.

5. Antenna: with three joints $=0$; with four joints $=1$ (Fig. 10 ); with five joints $=2$.

6. Relative size of antenna [length of antenna (A) / length of cranium (C)] [MMŠG: 5]: A/C (1 = 0 (Fig. 9); A/C > $1.1=1$.

7. Relative length of antennomeres [MMŠG: 6 , mod.]: second antennomere longer than the rest (first, third and fourth subequal) $=0$; first antennomere longer than the rest $=1$ (Fig 10 ); first segment as long as the apical segment $=2$. State 1 is a synapomorphy for Cetoniinae (with three subsequent independent changes to state 2 in Trichiina, Incaina and Schizorhinchini: Thaumastopeus). ci $=50 ; \mathrm{ri}=89 ; \mathrm{SW}=4$.

8. Number of dorsal sensory spots on antenna [MMŠG: 7 , mod.]: a single sensory spot $=0$; two or three $=1$ (Fig. $11 \mathrm{~b}$ ); four or more $=2$; one or two (states 0 and 1 can occur on the same specimen $)=3$.

9. Number of ventral sensory spots [MMŠG: 8 , mod.]: three or less than three $=0$ (Fig. 11a); four or more $=1$; three to five (both states 0 and 1 can occur on a single specimen) $=2$.

10. Shape of epipharynx [MMŠG: 9]: asymmetric $=0$; bilobed or not lobed $=1$ (Fig. 12 ); trilobed $=2$. State 1 is a synapomorphy for Trichiina + Cryptodontina + Valgini (with a parallelism in Incaina: Archedinus). ci=28; $\mathrm{ri}=73 ; \mathrm{SW}=2$.

11. Clithrum of epipharynx [MMŠG: 10 , mod.]: present $=0$; absent $=1$ (Fig. 12); present, absent, or variable in each specimen $=2$. State 0 is a synapomorphy for Osmodermatina + Cetoniinae s. str. (with a parallelism in Dynastinae). $\mathrm{ci}=50$, $\mathrm{ri}=90 ; \mathrm{SW}=4$.
12. Sclerotized plate on epipharynx [MMŠG: 11]: absent $=0$ (Fig. 12); present $=1$.

13. Sensory cone on haptolachus of epipharynx [MMŠG: 12, mod.]: sensory cone well developed $=0$ (Fig. 12); well defined but extremely reduced (tiny cone) $=1$; sensory cone not defined $=2$. We consider a sensory cone as reduced when the apical sensilla remains in a sensory field on a large oval plate.

14. Third nesium (next to laeotorma): present $=0$; absent $=1$ (Fig. 12)

15. Vestiture on haptomerum of epipharynx [MMŠG: 13]: bare $=0$; with a transverse row of stout setae interrupted by the haptomeral process $=1$; with transverse $\operatorname{row}(\mathrm{s})$ of stout setae under the haptomeral process $=2$ (Fig. 12). State 1 is a synapomorphy for Trichiina. $\mathrm{ci}=28 ; \mathrm{ri}=72 ; \mathrm{SW}=2$.

16. Haptomerum of epipharynx [MMŠG: 14, mod.]: without heli $=0$ (Fig. 12); one to four heli $=1$; with more than four heli $=2$.

17. Sensilla on haptomerum [MMŠG: 15] (not illustrated): grouped on a more or less prominent cone $=0$; not grouped on a cone or absent $=1$.

18. Epizygum on epipharynx [MMŠG: 16]: present $=0$; absent $=1$ (Fig. 12)

19. Tormae on epipharynx: fused $=0$; separate $=1$ (Fig. 12).

20. Dexiotorma on epipharynx [MMŠG: 17]: straight $=0$ (Fig. 12); bent mesally $=1$. State 1 is a synapomorphy for Trichiina. $\mathrm{ci}=100 ; \mathrm{ri}=100 ; \mathrm{SW}=10$.

21. Pternotormae on epipharynx [MMŠG: 18, mod.]: present and extended mesally $=0$; not extended mesally or absent at least on one side $=1$ (Fig. 12).

22. Number of setae on acanthoparia of epipharynx [MMŠG: 19, mod.] (not illustrated): absent or less than four (if more than four then very short and indistinct $)=0$; more than five $=1$.

23. Plegmata on epipharynx [MMŠG: 20]: absent $=0$ (Fig. 12); present $=1$.

24. Proplegmata on epipharynx: absent $=0$ (Fig. 12); present $=1$.

25. Number of scissorial teeth on right mandible [MMŠG: 21, mod.]: two $=0$ (Fig. $14 \mathrm{a})$; three $=1$; four $=2$. State 1 is a synapomorphy for Incaina + Osmodermatina + Cetoniinae s. str. $\mathrm{ci}=66 ; \mathrm{ri}=95 ; \mathrm{SW}=6$.

26. Number of scissorial teeth on left mandible [MMŠG: 22]: four $=0$; three $=1$ (Fig. 13a); two $=2$. State 0 is a synapomorphy for Incaina + Osmodermatina + Cetoniinae s. str. (with a subsequent change to state 1 in two genera of Gymnetini). $\mathrm{ci}=28 ; \mathrm{ri}=72 ; \mathrm{SW}=2$.

27. Apex of mandible [MMŠG: 23]: tridentate $=0$; not tridentate $=1$ (Fig. 13c). Only in Valgus is there a single apical tooth, which is separated by a scissorial notch from the second tooth in dorsal view, and also by another notch from the third tooth in ventral view.

28. Stridulatory area on mandibles [MMŠG: 24]: absent or greatly reduced (less than four ridges, or only with indistinct microridges $)=0$; present $=1$ (Fig. 13b).

29. Lacinia and galea [MMŠG: 25]: not fused =0; fused, forming mala $=1$ (Fig. 15)

30. Number of unci of lacinia [MMŠG: 26]: three $=0$; two $=$ 1 ; only one or absent $=2$ (Fig. 16). State 2 is a synapomorphy for Cryptodontina + Valgini (with a parallelism in Incaina and one member of Gymnetini). ci=33; ri=78; $\mathrm{SW}=2$.

31. Number of stridulatory teeth on maxilla [MMŠG: 27 , mod.]: less than four, or more than four, but the stridulatory teeth extremely reduced $=0$ (Fig. 15); five or more normally developed teeth $=1$. State 0 is a synapomorphy for Trichiina + Cryptodontina + Valgini. ci $=100 ; \mathrm{ri}=100 ; \mathrm{SW}=10$. 
32. Tegumentary expansions on right side of hypopharyngeal scleroma (just below scleroma) [MMŠG: 28]: present $=0$; absent $=1$ (Fig. 15).

33. Tegumentary expansions on left side of hypopharyngeal scleroma [MMŠG: 29]: present $=0$ (Fig. 15); absent $=1$.

34. Spiracles (not illustrated): biforous $=0$; cribriform $=1$.

35. Number of holes in respiratory plate of thoracic spiracle [MMŠG: 30] (not illustrated): $0-15$ holes across diameter $=0$; $16-59$ holes across diameter $=1$; more than 60 tiny holes across diameter $=2$.

36. Relative size of legs [MMŠG: 31]: three pairs of legs of different size, length increasing from first to third pair $=0$; all pairs of similar size $=1$ (Fig. 3). State 1 is a synapomorphy for Cetoniinae (with a parallelism in Trox). $\mathrm{ci}=50 ; \mathrm{ri}=93 ; \mathrm{SW}=4$.

37. Last segment of legs [MMŠG: 32, mod.]: with weakly developed claw with two setae $=0$ (Fig. 19); tarsungulus with several setae and a well developed sclerotized claw $=1$; tarsungulus with several setae and a tiny sclerotized claw at apex $=2$; tarsungulus with several setae $=3$.

38. Relative size of leg segments [MMŠG: 33, mod.]: trochanter longer than tibiotarsus $=0$; trochanter shorter than tibiotarsus $=1$ (Fig. 18).

39. Abdominal segments IX and X [MMŠG: 34$]$ : not fused = 0 (Fig. 3); fused $=1$. State 1 is a synapomorphy for Osmodermatina + Cetoniinae s. str. (with reversal in Goliathini: Goliathus). ci=50; ri=96; $\mathrm{SW}=4$.

40. Palidium on raster of last abdominal segment [MMŠG: 35]: absent $=0$ (Fig. 20); present $=1$.

41. Hamate setae on raster of last abdominal segment [MMŠG: 36]: absent $=0$ (Fig. 20); present $=1$.

42. Anal slit [MMŠG: 37]: transverse $=0$ (Fig. 20); Y-shaped $=1$.

43. Anal tergite [MMŠG: 38]: with an area demarked by a special sulcus $=0$; without sulcus $=1$ (Fig. 3 ).

Adults

44. Surface of frons [MMŠG: 39]: convex $=0$; concave $=1$; with accessories $=2$.

45. Clypeal surface [MMŠG: 40]: flattened or slightly convex $=0$; slightly concave $=1$, deeply concave or excavated $=2$. State 2 is a synapomorphy for Incaina (with numerous parallelisms outside this clade). $\mathrm{ci}=13 ; \mathrm{ri}=40 ; \mathrm{SW}=0$.

46. Anterior border of male clypeus [MMŠG: 41]: straight, slightly curved or sinuate $=0$; clearly notched $=1$; armed $=2$. State 2 is a synapomorphy for Incaina (with parallelism in Cryptodontina and other cases outside Incaina). $\mathrm{ci}=16$; $\mathrm{ri}=56$; $\mathrm{SW}=0$.

47. Ventral surface of labium [MMŠG: 42]: flattened or convex $=0$; partially or slightly concave $=1$; completely or deeply concave $=2$.

48. Anterior border of labrum [MMŠG: 43]: exposed $=0$; hidden $=1$. Weakly sclerotized labrum is reduced or completely covered by clypeus and other mouthparts.

49. Preocular notch [MMŠG: 44]: absent $=0$; present $=1$. State 1 is a synapomorphy for Cetoniinae. $\mathrm{ci}=100$; $\mathrm{r}=100$; $\mathrm{SW}=10$.

50. Antennal scapus [MMŠG: 45]: rounded $=0$; widened and depressed $=1$. Anterior and posterior border of the basal antennomere clearly expanded, offering a nearly flattened external surface that covers the antennal insertion when disturbed.

51. Length of male antennal club [MMŠG: 46]: as long as or shorter than funicle $=0$; clearly longer than funicle $=1$.

52. Sexual dimorphism of head [MMŠG: 47]: absent $=0$; slight $=1$; accentuated $=2$. State 2 is a synapomorphy for Incaina (with numerous parallelisms outside this clade). $\mathrm{ci}=15$; $\mathrm{ri}=68 ; \mathrm{SW}=1$.
53. Apex of galea [MMŠG: 48]: toothed $=0$; rounded, not toothed $=1$. State 1 is a synapomorphy for Cetoniinae s. str. except Cremastocheilus (with two parallelisms outside and one reversal inside this clade). ci=14; $\mathrm{ri}=71 ; \mathrm{SW}=1$.

54. Central third of posterior border of pronotum [MMŠG: 49]: straight or curved $=0$; clearly sinuate $=1$; lobed $=2$. Backward expansion of the posterior pronotal border forms a rounded lobe usually covering most of scutellum. A sinuate posterior pronotal border projects beyond the basal border of scutellum.

55. Pronotal disc [MMŠG: 50, mod.]: simply convex $=0$; with depressions or prominences $=1$; with depression and prominences only in males $=2$.

56. Basal third of pronotum [MMŠG: 51]: reduced $=0$; projected $=1$. State 1 is a synapomorphy for Cetoniinae s. str. except Cremastocheilus (with three parallelisms outside this clade). $\mathrm{ci}=25 ; \mathrm{ri}=85 ; \mathrm{SW}=2$.

57. Anterolateral border of pronotum [MMŠG: 52]: with margin $=0$; without margin, rounded $=1$.

58. Procoxae [MMŠG: 53]: transverse, slightly prominent $=$ 0 ; nearly conical and clearly prominent $=1$. State 1 is a synapomorphy for Cetoniinae (with a subsequent reversal in Cryptodontini). ci=33; ri=87; $\mathrm{SW}=2$.

59. Metacoxae [MMŠG: 54]: close together $=0$; widely separated $=1$.

60. Posterolateral corner of metacoxa [MMŠG: 55]: short, rounded $=0$; prominent, acute $=1$.

61. Inner sides of base of protibia [MMŠG: 56]: without tooth $=0$; with tooth $=1$. State 1 is a synapomorphy for Incaina. $\mathrm{ci}=100 ; \mathrm{ri}=100 ; \mathrm{SW}=10$.

62. External border of male protibia [MMŠG: 57, mod.]: with two to three teeth $=0$; without a tooth or with an apical one $=1$.

63. Inner border of male protibia [MMŠG: 58 , mod.]: simple $=0$; toothed or serrate $=1$.

64. Preapical ventral border of protibia [MMŠG: 59]: simple, flattened $=0$; toothed $=1$. State 1 is a synapomorphy for Incaina + Osmodermatina + Cetoniinae s. str. (with four reversals inside Cetoniinae s. str. and parallelism in two among three members of Valgini). ci=12; ri=30; $\mathrm{SW}=0$.

65. Dorsal surface of mesotibia [MMŠG: 60]: with keels or spines $=0$; without keels or spines $=1$.

66. Dorsal surface of metatibia [MMŠG: 61]: with keels or spines $=0$; without keels or spines $=1$.

67. Sexual dimorphism of protarsus [MMŠG: 62]: absent $=0$; slight $=1$; accentuated $=2$.

68. Onychium [MMŠG: 63]: long $=0$; short $=1$; absent $=2$. We take as a reference the dorsoventral basal width of one tarsal claw (as long as the dorsoventral basal width of tarsal claw or shorter).

69. Preprosternum [MMŠG: 64]: without projection $=0$; with erect tubercle or strong spine $=1$. State 1 is a synapomorphy for Incaina (with numerous parallelisms outside this clade). $\mathrm{ci}=7$ $\mathrm{ri}=47 \mathrm{SW}=0$.

70. Postprosternum [MMŠG: 65]: without projection $=0$; with erect tubercle or strong spine $=1$.

71. Mesometasternum [MMŠG: 66]: without projection $=0$; with tubercle $=1$. State 1 is a synapomorphy for Cetoniinae s. str. except Cremastocheilus (with one parallelism and one reversal outside and inside this clade, respectively). ci=33; $\mathrm{ri}=92 ; \mathrm{SW}=3$.

72. Proepimeron [MMŠG: 67]: nearly flattened or scarcely concave $=0$; deeply concave $=1$. The strong and wide depression on the proepimeron in a number of Cetoniinae allows for the reception of the basal distal half of the profemur and as a consequence, the thickness of the latero-posterior side of pronotum is reduced. 
73. Dorsal part of mesepimeron [MMŠG: 68]: completely covered or nearly so $=0$; clearly exposed $=1$. State 1 is a synapomorphy for all Cetoniinae s. str. (with two reversals inside this clade). $\mathrm{ci}=33 ; \mathrm{ri}=92 ; \mathrm{SW}=3$.

74. Proepisternal keel [MMŠG: 69]: absent or weakly defined $=0$; clearly defined and outstanding $=1$.

75. Scutellum [MMŠG: 70]: completely exposed $=0$; partly covered or completely covered $=1$.

76. Posthumeral elytral emargination [MMŠG: 71]: weak or absent $=0$; wide and deep, well defined $=1$. State 1 is a synapomorphy for all Cetoniinae s. str. (with two reversals inside this clade). $\mathrm{ci}=33 ; \mathrm{ri}=92 ; \mathrm{SW}=3$.
77. Fifth abdominal sternum [MMŠG: 72]: nearly as long as fourth $=0$; longer than fourth $=1$.

78. Fifth abdominal spiracle [MMŠG: 73]: annular $=0$; tuberculiform $=1$.

79. Pygidium [MMŠG: 74]: wider than long $=0$; as long as wide, or slightly longer than wide $=1$.

80. Propygidium [MMŠG: 75]: covered by elytra $=0$; largely exposed $=1$.

81. Dorsal vestiture [MMŠG: 76]: absent $=0$; setiferous $=1$; pruinose or cretaceous $=2$. State 2 is a synapomorphy for Trichiina (with one reversal inside this clade and multiple reversals and parallelisms outside it). $\mathrm{ci}=9 ; \mathrm{ri}=34 ; \mathrm{SW}=0$. 